\title{
Prostaglandins in the umbilical and uterine circulations during late pregnancy in the ewe
}

\author{
M. D. Mitchell, J. Brunt, L. Clover and D. W. Walker* \\ Nuffield Department of Obstetrics and Gynaecology, and * Nuffield Institute for Medical \\ Research, University of Oxford, John Radcliffe Hospital, Headington, Oxford OX3 9DS, U.K.
}

\begin{abstract}
Summary. Prostaglandins (PG) E and F, and 13,14-dihydro-15-keto-prostaglandin $F$ (PGFM) were measured in plasma collected from the umbilical artery and vein, the maternal carotid artery, and the utero-ovarian vein of pregnant sheep between 116 and 139 days of gestation. PGE levels were greater than PGF levels in the umbilical artery and vein and the maternal carotid artery, but not in the uteroovarian vein. PGFM exceeded PGF in samples from all vessels. There was a significant vein-to-artery concentration difference for PGF and PGFM, but not for PGE, in the umbilical circulation. Utero-ovarian concentrations of all 3 PGs generally exceeded their concentrations in the maternal carotid artery.
\end{abstract}

\section{Introduction}

It has been shown that prostaglandin (PG) E may be of importance in the control of fetal and placental haemodynamics (Novy, Piasecki \& Jackson, 1974; Rankin \& Phernetton, 1976a, b) and in the maintenance of tone of the ductus arteriosus (Coceani, Olley \& Bodach, 1976). Prostaglandins also influence fetal adrenal production of corticosteroids (Louis, Challis, Robinson \& Thorburn, 1976).

PGE has been measured in the fetal circulation of sheep (Challis, Dilley, Robinson \& Thorburn, 1976) and its plasma concentration is raised at delivery. The source of this PGE is unknown although it has been suggested that it may originate in part from the fetal cotyledon (Mitchell \& Flint, 1977, 1978). In man the placenta may also be a source of the PGE in the fetal circulation since umbilical venous plasma obtained after spontaneous vaginal delivery has a significantly greater concentration of PGE than corresponding arterial samples (Mitchell et al., 1978a). We have therefore measured PGs in the umbilical and uterine circulations of chronically catheterized fetal sheep and ewes to determine whether arterio-venous differences exist for these substances across the uterus and fetal side of the placenta.

\section{Materials and Methods}

Animals. Four sheep of mixed breed were used. The day of marking by an intact ram was taken as Day 0 of pregnancy. Catheters were implanted on Days 112-115 into a maternal carotid artery and utero-ovarian vein and into a fetal femoral artery (which contains blood of the same composition as the umbilical artery) using strictly aseptic procedures (Dawes, Fox, Leduc, Liggins \& Richards, 1972). A catheter (1.0 mm i.d.) was also inserted into the common umbilical vein through a purse-string suture $(5 / 0$ silk) as described by Young, Creasy \& Rudolph (1974). The fetal catheters were infused continuously with a heparin-saline solution 
( 250 units $/ \mathrm{ml}$ ) beginning $3 \mathrm{~h}$ after the completion of surgery. Arterial and venous samples were taken from the fetal catheters between Days 116 and 119, Days 117 and 130, Days 121 and 136, and Days 134 and 146 in the 4 animals. Maternal arterial and venous samples were collected simultaneously from 2 of the ewes. Three ewes spontaneously delivered live lambs at term and in the other the fetus died in utero on Day 126 of pregnancy. Only samples collected 7 days before delivery or the fetal death have been used for the statistical analysis. The condition of the fetus was assessed at the time of sampling each day by measurement of the arterial $\mathrm{pH}$ and blood gas tensions of $\mathrm{O}_{2}$ and $\mathrm{CO}_{2}$. During the periods of sampling the ranges were: 7.307.38 for $\mathrm{pH}, 18-24 \mathrm{mmHg}$ for $\mathrm{Po}_{2}$, and 44-55 $\mathrm{mmHg}$ for $\mathrm{PCO}_{2}$. There was little variation in these values throughout the period when samples were collected from each fetus. Blood samples for estimation of PGs were collected into ice-cold heparinized tubes and centrifuged immediately at $2000 \mathrm{~g}$ and $4^{\circ} \mathrm{C}$; the plasma was separated and stored at $-20^{\circ} \mathrm{C}$ until assay. Blood samples for $\mathrm{pH}$ and blood gases were collected into $1 \mathrm{ml}$ glass syringes and stored on ice for no more than 15 min before they were measured.

Radioimmunoassay. PGE, PGF and 13,14-dihydro-15-keto-prostaglandin F (PGFM, a metabolite of PGF) were measured by specific radioimmunoassays as described previously (Mitchell et al., 1978a, b). The methods utilize an extraction and chromatographic step before final radioimmunoassay. The procedures were validated for use in maternal and fetal sheep plasma. Accuracy was assessed by the addition of known amounts of each prostaglandin $(0-$ $300 \mathrm{pg}$ ) in triplicate to maternal and fetal plasma. Evaluation of the recoveries of added standards after correction for endogenous concentrations are presented in Table 1. The mean intra-assay coefficients of variation for the assay of PGE, PGF and PGFM were 7.8, 6.9 and $7.0 \%$ respectively. The inter-assay coefficients of variation during the time of this study, using 200 pg pools, were 16, 16 and $9 \%$ for PGE, PGF and PGFM respectively. Solvent blanks were consistently $<2 \mathrm{pg}$ in each assay. Cross-reactivity with other prostanoids are low with these methods (Mitchell et al., 1978b).

Table 1. Accuracy of the prostaglandin (PG) radioimmunoassays

\begin{tabular}{|c|c|c|c|c|}
\hline \multirow[b]{2}{*}{ PG added } & \multicolumn{2}{|l|}{ Maternal plasma } & \multicolumn{2}{|l|}{ Fetal plasma } \\
\hline & Regression & $r^{*}$ & Regression & $r^{*}$ \\
\hline PGE & $y \dagger=0.96 x \neq+1.43$ & 0.99 & $y=0.95 x-0.59$ & 0.99 \\
\hline PGF & $y=1.04 x-1.19$ & 0.97 & $y=1.09 x+6.45$ & 0.98 \\
\hline PGFM & $y=1.04 x-0.39$ & 0.99 & $y=0.84 x+2.28$ & 0.99 \\
\hline
\end{tabular}

Statistical analysis. The data for the PGs from each fetus and ewe were pooled, and the mean \pm s.e.m. calculated. The concentration differences of the various PGs for each pair of arterial and venous samples were also pooled and averaged. Bartlett's test was used to show that the variances of the arterio-venous differences were not different between fetuses for each of the PGs or different for the set of PGE and PGF samples from each of the different catheters from each fetus, and it was therefore permissible to pool the data. The variances of the PGF and PGFM data from each of the fetal vessels were significantly different and these data were not compared statistically. Also, the scatter of the set of utero-ovarian and arterial values from the 2 ewes was such that they could not be pooled, and no statistical test was wholly appropriate. To determine the significance of the difference between arterial and venous levels of each PG, and also of the difference between the three PGs in plasma from the same source, a form of weighted $t$ test was used. The weighting chosen was such that the data from each of the four fetuses contributed equally to the test statistic even though there were more readings from some fetuses 
than others. The null hypotheses under test were (a) that the mean arterio-venous concentration difference for each PG was zero, and (b) that the concentration difference between the various PGs from the same source was zero. Correlations were determined by the Spearman Rank correlation coefficient.

Table 2. Plasma concentrations of prostaglandins (PG) in the fetal lamb and ewe during late pregnancy

\begin{tabular}{lcrrrrr}
\hline & & & \multicolumn{3}{c}{ Mean \pm s.e.m. PG conc. (pg/ml) } \\
\cline { 5 - 6 } \multicolumn{1}{c}{ Source of plasma } & ewes & $\begin{array}{c}\text { No. of } \\
\text { samples }\end{array}$ & PGE & PGF & PGFM \\
\hline Fetus & & & & & & \\
$\quad$ Umbilical vein & 4 & 16 & $425 \pm 60$ & $279 \pm 50$ & $1352 \pm 173$ \\
$\quad$ Femoral artery & 4 & 16 & $394 \pm 53$ & $203 \pm 38$ & $1033 \pm 164$ \\
$\quad$ Vein-artery difference $\dagger$ & 4 & 16 & $31 \pm 33$ & $76 \pm 34^{*}$ & $319 \pm 69^{* *}$ \\
Ewe & & & & & \\
$\quad$ Utero-ovarian & 2 & 9 & $1289 \pm 110$ & $897 \pm 255$ & $2033 \pm 400$ \\
$\quad$ Carotid artery & 4 & 16 & $568 \pm 57$ & $122 \pm 21$ & $1151 \pm 208$ \\
$\quad$ Vein-artery difference $\dagger$ & 2 & 9 & $718 \pm 152$ & $789 \pm 235$ & $896 \pm 241$ \\
\hline
\end{tabular}

$* P<0.05, * * P<0.001$, significantly different from zero concentration difference.

+ Venous--arterial differences are the means of all pairs of vein and artery samples.
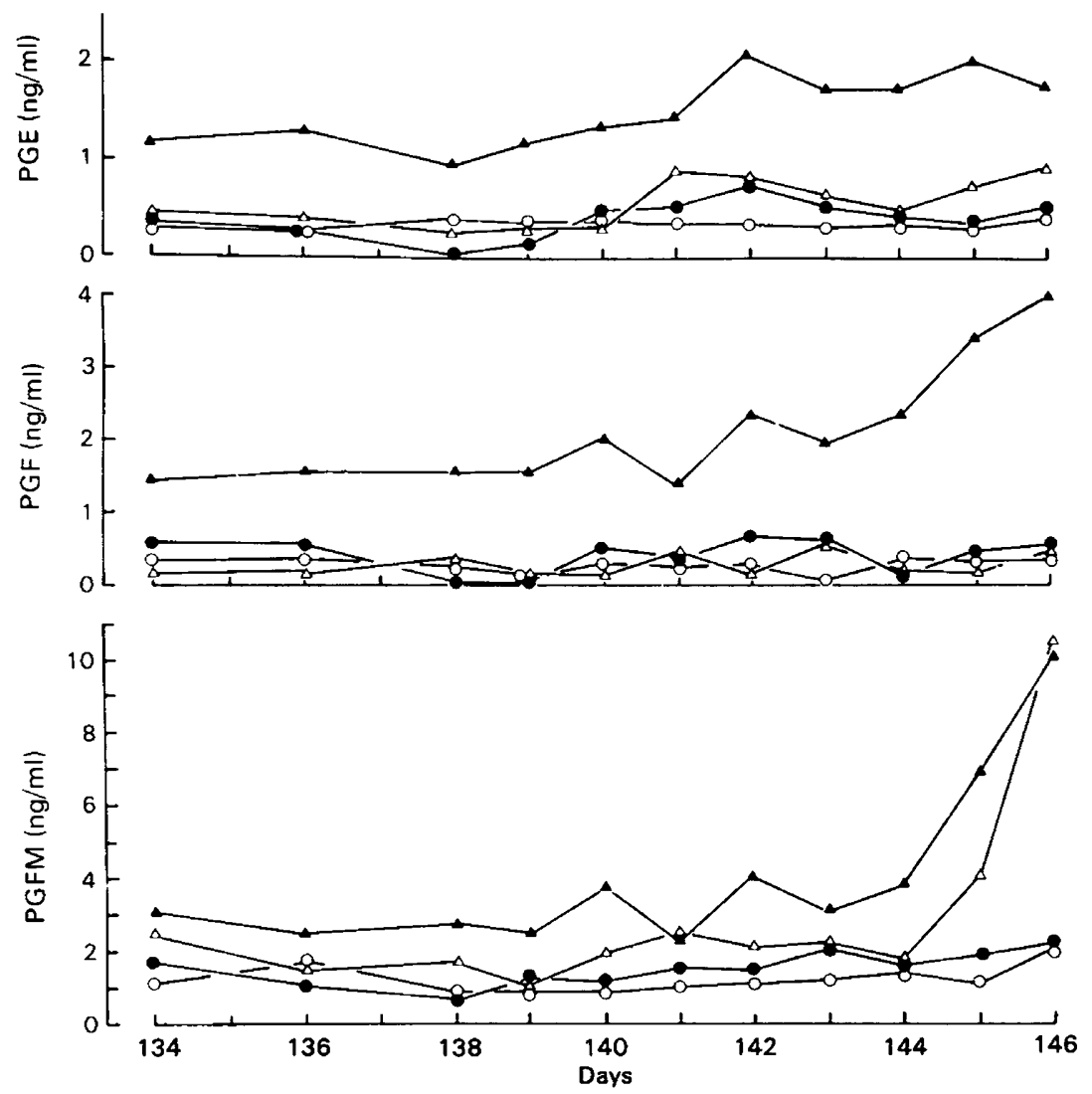

Text-fig. 1. Plasma concentrations of prostaglandins (PGs) during late pregnancy and parturition in a ewe which gave birth on Day 146 of pregnancy. $O$, fetal femoral (umbilical) artery; fetal umbilical vein; $\Delta$ maternal carotid artery; $\Delta$ utero-ovarian vein. 


\section{Results}

The concentrations of PGs in maternal and umbilical plasma from the 4 sheep (3-5 samples/sheep) between Days 116 and 139 of pregnancy are shown in Table 2. The concentration of PGFM was greater than PGF in all fetal and maternal samples, no matter what the source. The concentration of PGE was significantly greater than PGF in umbilical arterial $(P<$ $0.001)$ and venous $(P<0.005)$ plasma. There were higher levels of PGE than PGF in $8 / 9$ maternal arterial samples and in 5/9 utero-ovarian samples.

In the 2 ewes, from which arterial and utero-ovarian samples were collected, the venous concentration of all 3 PGs always exceeded the arterial concentration, although this could not be tested statistically. In the fetuses, there was a significant vein-to-artery concentration difference for PGF $(P<0.05)$ and PGFM $(P<0.001)$, but this was not so for PGE.

There was a significant correlation between the concentrations of PGE and PGF in both umbilical arterial and venous plasma $(P<0.005$ in each case), but not in maternal arterial or utero-ovarian plasma. There was a significant correlation between PGF and PGFM in maternal arterial $(P<0.005)$ and utero-ovarian venous $(P<0.01)$ plasma, but not in the samples from the umbilical circulation.

Serial samples were obtained in one animal during the 14 days before birth of a live lamb at term (Day 146). As shown in Text-fig. 1, the usual trend for maternal concentrations of PGF and PGFM to increase during parturition was observed, and a small increase in maternal PGE levels was also noted. The umbilical venous concentration of PGE increased slightly in the week before delivery, but no other trends were apparent.

\section{Discussion}

This study has shown that a significant arterio-venous difference exists for PGF and PGFM across the umbilical circulation during pregnancy in the sheep. The higher venous levels of both compounds suggests that the placenta is a major source of these prostaglandins in the fetal circulation. It is not clear why PGE does not also show a vein-to-artery concentration difference since its production by the fetal placenta in vitro is very high (Mitchell \& Flint, 1978). It is still technically difficult to assay the major metabolite of PGE (13,14-dihydro-15-keto-prostaglandin E) because of its instability in aqueous media (Mitchell, Sors \& Flint, 1977) and the influence of the metabolism of PGE by the fetal cotyledon in vivo (Keirse, Mitchell \& Flint, 1977) or other fetal tissues (Pace-Asciak, 1976) cannot be assessed.

The arterio-venous differences across the uterus for PGF and PGFM noted by us are verifcation of previous suggestions that such differences exist (Liggins \& Grieves, 1971; Mitchell, Flint \& Turnbull, 1976; Keirse et al., 1977). It was not unexpected that PGE would show a similar arterio-venous difference but the actual concentrations measured were higher than had been expected from previous data (Challis et al., 1976). The production in vitro of considerable quantities of PGE by uterine tissues (Mitchell \& Flint, 1978) would be consistent with the high levels found in utero-ovarian venous plasma.

The relative quantitative order of PGs in umbilical plasma (PGFM > PGE >PGF) is similar to that found in human umbilical plasma (Mitchell et al., 1978a). The high concentration of PGFM is consistent with the known metabolizing activities of fetal tissues (Pace-Asciak, 1976; Keirse et al., 1977). The small umbilical arterio-venous difference for PGE appears at variance with previous data for man (Mitchell et al., 1978a) but the high umbilical venous PGE levels found in women were from samples obtained after spontaneous labour, while the present results were from late pregnant sheep before the onset of labour. In the one ewe sampled until parturition the PGE concentration was greater in umbilical venous plasma than in umbilical arterial plasma during the week immediately before delivery, but not in the week preceding this 
(Text-fig. 1). This arterio-venous difference was brought about by an increase in umbilical vein plasma PGE concentrations without a change in the arterial concentrations. It is therefore possible that some factor associated with parturition causes an increase of PGE production by the fetal cotyledon, and this leads to increased concentrations of PGE in umbilical vein plasma. Challis et al. (1976) have reported that fetal arterial concentrations of PGE increase in the 12$24 \mathrm{~h}$ before birth of the lambs. We are unable to verify this because of insufficient samples.

We thank Professor G. S. Dawes and Professor A. C. Turnbull for their encouragement and use of departmental facilities. Authentic PGs were the gift of Dr J. E. Pike, (Upjohn Co., Kalamazoo) and PG antisera were generously donated by Dr F. Dray (Pasteur Institute, Paris). Statistical help and advice were kindly given by Dr J. Bithell and Mrs J. Pierce (Department of Biomathematics, University of Oxford), Dr L. Barr (Oxford Regional Health Authority) and Mrs P. Yudkin (Nuffield Department of Obstetrics \& Gynaecology, University of Oxford). D.W.W. was a Nuffield Dominions Demonstrator; M.D.M. acknowledges receipt of the Staines Medical Research Fellowship (Exeter College, Oxford), and the work was supported by the M.R.C.

\section{References}

Challis, J.R.G., Dilley, S.R., Robinson, J.S. \& Thorburn, G.D. (1976) Prostaglandins in the circulation of the fetal lamb. Prostaglandins 11, 1041-1052.

Coceani, F., Olley, P.M. \& Bodach, E. (1976) Prostaglandins: a possible regulator of muscle tone in the ductus arteriosus. In Advances in Prostaglandin and Thromboxane Research, vol. 1, pp. 417-424. Eds B. Samuelsson \& R. Paoletti. Raven Press, New York.

Dawes, G.S., Fox, H.E., Leduc, B.M., Liggins, G.C. \& Richards, R.T. (1972) Respiratory movements and rapid eye movement sleep in the fetal lamb. $J$. Physiol., Lond. 220, 119-143.

Keirse, M.J.N.C., Mitchell, M.D. \& Flint, A.P.F. (1977) Changes in myometrial and placental 15-hydroxyprostaglandin dehydrogenase with ovine parturition: production of prostaglandin metabolites in vitro and in vivo. J. Reprod. Fert. 51, 409-412.

Liggins, G.C. \& Grieves, S.A. (1971) Possible role for prostaglandins in parturition. Nature, Lond. 232, $629-631$.

Louis, T.M., Challis, J.R.G., Robinson, J.S. \& Thorburn, G.D. (1976) Rapid increase of foetal corticosteroids after prostaglandin $\mathrm{E}_{2}$. Nature, Lond. 264, 797-799.

Mitchell, M.D. \& Flint, A.P.F. (1977) Prostaglandin concentration in intra-uterine tissues from late pregnant sheep before and after labour. Prostaglandins 14, 563-569.

Mitchell, M.D. \& Flint, A.P.F. (1978) Prostaglandin production by intra-uterine tissues from periparturient sheep: use of a superfusion technique. $J$. Endocr. 76, 111-121.

Mitchell, M.D., Flint, A.P.F. \& Turnbull, A.C. (1976) Plasma concentrations of 13,14-dihydro-15-keto- prostaglandin F during pregnancy in sheep. Prostaglandins 11, 319-329.

Mitchell, M.D., Sors, H., \& Flint, A.P.F. (1977) Instability of 13,14-dihydro-15-keto-prostaglandin $\mathrm{E}_{2}$. Lancet ii, 558.

Mitchell, M.D., Brunt, J., Bibby, J., Flint, A.P.F., Anderson, A.B.M. \& Turnbull, A.C. (1978a) Prostaglandins in the human umbilical circulation at birth. Br. J. Obstet. Gynaec. 85, 114-118.

Mitchell, M.D., Flint, A.P.F., Bibby, J., Brunt, J., Arnold, J.M., Anderson, A.B.M. \& Turnbull, A.C. (1978b) Plasma concentrations of prostaglandins during late human pregnancy. Influence of normal and pre-term labour. J. clin. Endocr. Metab. 46, 947-951.

Novy, M.J., Piasecki, G. \& Jackson, B.T. (1974) Effect of prostaglandin $E_{2}$ and $F_{2 \alpha}$ on umbilical blood flow and fetal haemodynamics. Prostaglandins 5, 543555.

Pace-Asciak, C. (1976) Biosynthesis and catabolism of prostaglandins during animal development. In Advances in Prostaglandin and Thromboxane Research, vol. 1, pp. 35-46. Eds B. Samuelsson \& R. Paoletti. Raven Press, New York.

Rankin, J.H.G. \& Phernetton T.M. (1976a) Effect of prostaglandin $\mathrm{E}_{2}$ on ovine maternal placental blood flow. Am. J. Physiol. 231, 754-759.

Rankin, J.H.G. \& Phernetton, T.M. (1976b) Circulatory responses of the near term sheep fetus to prostaglandin $\mathrm{E}_{2}$. Am.J. Physiol. 231, 760-765.

Young, W.P., Creasy, R.K. \& Rudolph, A.M. (1974) Catheterization of the common umbilical vein for chronic fetal lamb studies. J. appl. Physiol. 37, 620621.

Received 12 February 1979 